\title{
« Fiscal policy, institutional quality and central bank transparency "
}

\author{
$\underline{\text { Auteurs }}$ \\ M. Dai, M. Sidiropoulos, E. Spyromitros \\ Document de Travail $n^{\circ} 2014-4$
}

Mars 2014

Faculté des sciences économiques et de gestion Pôle européen de gestion et d'économie (PEGE) 61 avenue de la Forêt Noire F-67085 Strasbourg Cedex

Secrétariat du BETA Géraldine Del Fabbro Tél. : (33) 0368852069 Fax : (33) 0368852070 g.delfabbro @unistra.fr www.beta-umr7522.fr 


\title{
Fiscal policy, institutional quality and central bank transparency
}

\author{
Meixing Dai* \\ BETA, University of Strasbourg, France \\ Moïse Sidiropoulos \\ BETA, University of Strasbourg, France, and LEAP, Aristotle University of Thessaloniki, Greece \\ Eleftherios Spyromitros \\ Democritus University of Thrace, Greece, and BETA, University of Strasbourg, France
}

\begin{abstract}
This paper examines monetary and fiscal interactions in a framework where the government worries about political costs of low institutional quality and central bank opacity acts as a disciplinary device leading the government to reduce distortionary taxes and public expenditures. Greater opacity could thus lower the reactions of inflation expectations and inflation but increase those of the output gap to supply shocks and the target of public expenditures, and would be beneficial in terms of less macroeconomic volatility. Under the least favourable assumptions on the effect of corruption, i.e. 'sanding-the-wheels' effect or weak 'greasing-the-wheels' effect, we have shown that there is a fiscal disciplining effect of central bank opacity in a game framework where the government is a Stackelberg leader. Imperfect transparency could increase corruption only if the 'greasing-the-wheels' effect is relatively large. These results could be reinforced by the presence of grand corruption.
\end{abstract}

Key words: Central bank opacity, fiscal disciplining effect, distortions, institutional quality, corruption.

JEL classification: D73, E52, E58, E61, E63, H50.

* Corresponding author: Meixing Dai (dai@unistra.fr). 


\section{Introduction}

Weak public institutions, including high levels of corruption, are clearly prevalent in emerging market economies and they are present even in some advanced Western economies as shown by indices developed by the World Bank (Kaufmann et al., 2007) and Transparency International (TI, 2012). ${ }^{1}$ Some theoretical and empirical studies highlighted the nexus between corruption and inflation, showing divergent conclusions according to the types of corruption considered. For instance, Al-Marhubi (2000), Smith-Hillman (2007) and Blackburn and Powell (2011) have found a positive link between petty corruption and inflation. This link could be reversed if grand corruption is considered (Bohn, 2013). ${ }^{2}$

Several recent studies have emphasised the role of weak public institutions in determining monetary and fiscal policy design as well as the choice of exchange rate regime in developing countries. Huang and Wei (2006) have shown that weak institutions, modelled as exogenous erosion in the ability of government to collect revenue through formal tax channels, have important implications for the design of monetary policymaking institutions. Hefeker (2010) considers that the government endogenously chooses the optimal level of institutional quality (i.e. the quality of institutions and governance, with corruption as an important indicator of bad institutions) and has found that credibly pegging exchange rate to an anchor currency can reduce corruption and improve the fiscal system. Popkova (2010) has shown that, if corruption has a considerable positive impact on output, a tight peg increases the level of corruption.

\footnotetext{
${ }^{1}$ A strand of empirical literature investigates the effects of institutions on development (Rose-Ackerman, 1975; Shleifer and Vishny, 1993; Mauro, 1995; Méon and Sekkat, 2005) and the consequences of corruption for international capital flows, tax evasion, and stock market volatility (Wei, 2000; Fisman and Wei, 2004; Du and Wei, 2004).

${ }^{2}$ Corruption can be generally defined as the individual's (illegal) attempt to reap private benefits from public office. The terms such as petty corruption or bribery refers to government employees, and grand corruption means that the leadership uses its policy setting power for obtaining some personal advantage.
} 
The International Monetary Fund (IMF) has adopted at the end of the 1990s a code of good conduct to increase the transparency of official operations, including transparency of monetary policies, in emerging market economies. This is in part prompted by the 1994 peso and other emerging market crises (Wilson and Saunders, 2004; de Mendonça and Filho, 2008). However, the benefit of central bank transparency in the context of low institutional quality (corruption) remains an unexplored topic in the current literature on monetary and fiscal policy interactions. ${ }^{3}$

This paper provides a theoretical study about how corruption (low institutional quality) could affect monetary and fiscal policy interactions with opacity (intransparency or imperfect transparency) about central bank preferences. ${ }^{4}$ We consider a benevolent government as a Stackelberg leader with objectives of stabilising inflation, output and public expenditures and corruption. An independent central bank as Stackelberg follower shares with the government the same objectives of inflation and output. Corruption is assumed to negatively affect the fiscal revenue of the government and either negatively ('sanding-the-wheels' effect) or positively ('greasing-the-wheels' effect) the supply function. The latter is negatively affected by another kind of endogenous distortion, i.e., distortionary taxes. The corruption considered here is petty corruption, which could improve the efficiency of existing firms or allow entrepreneurs to realise more productive projects by corrupting officials (Coppier and Michetti, 2006; Lambert-Mogiliansky et al., 2007).

The central bank would like to decrease inflation by being intransparent about its preferences in order to incite the government to reduce the tax rate and public expenditures. In

\footnotetext{
3 Transparency implies that the central bank provides the general public and market operators with all relevant information about its monetary policy strategy, economic assessments and policy decisions as well as its decisional and operational procedures in an open, clear and timely manner. Eijffinger and Geraats (2006) have developed indices of central bank transparency, which are expanded by Dincer and Eichengreen (2007).

4 There are five motives for central bank transparency, i.e. political, economic, procedural, policy and operational transparency (Geraats, 2002). Transparency about central bank preferences, following this terminology, can be considered as political transparency which refers to openness about policy objectives and institutional arrangements.
} 
effect, distortionary taxes imply higher expected and current inflation, and lower output gap. The government perceives that marginal costs associated with higher taxes are higher when the central bank is more intransparent. Under Brainard's (1967) conservatism principle, the government will adopt a less aggressive fiscal policy (i.e., 'disciplining effect'). This stance of fiscal policy leads to lower inflation and higher output at the cost of a larger deviation of public expenditures from their target.

The introduction of corruption in the objective function and the budget constraint of the government and in the supply function offers the government more trade-offs to consider but also an additional instrument. Generally, opacity has a fiscal disciplining effect which depends on the 'sanding-the-wheels' or 'greasing-the-wheels' effect of corruption and the initial level of opacity. This disciplining effect dominates if the 'greasing-the-wheels' effect is relatively low or when corruption has a 'sanding-the-wheels' effect. However, the government, while being disciplined by opacity, accepts a higher level of corruption if the 'greasing-the-wheels' effect is relatively large. Finally, when the latter is very large, the government, in response to an increase in opacity, would choose to reduce the tax rate but also corruption, leading to higher inflation and a lower output gap. Regarding the macroeconomic performance, opacity reduces the volatility of inflation and the output gap if the initial degree of opacity is sufficiently high. Introducing grand corruption in the government's objective function could significantly reinforce our main findings.

Our results could have relevant implications not only for emerging market economies but also some developed countries characterised by substantial corruption. ${ }^{5}$ According to our results, central bank transparency could be beneficial only when corruption has a very large 'greasing-the-wheels' effect. Given that the 'sanding-the-wheels' effect is dominant according

\footnotetext{
${ }^{5}$ For example, many emerging countries in Latin America (e.g., Argentine and Mexico), Asia (e.g., India and Pakistan) and Africa are characterised by high inflation and high level of corruption. Some developed countries such as Portugal, Italy, Greece and Spain were in this situation before they joined the Euro Zone. See Kaufmann et al. (2007) and TI (2012).
} 
to empirical studies (Aidt, 2009), our results do not support the recommendation of transparency in monetary policies by the IMF. They suggest that intransparency has a role to play in stabilising the economy in countries subject to low institutional quality and high level of corruption because it could have a fiscal disciplining effect. Our recommendation for intransparent monetary policies is reinforced if the government of such a country is also submitted to implicit or explicit ceilings in public debt, grand corruption, and high political costs of corruption when making fiscal policy decisions. Furthermore, our results could explain various patterns of corruption and macroeconomic stability in association with different degrees of central bank intransparency, and thus could provide a useful guide for empirical investigations and policy making.

The paper is closely related to the general literature on central bank transparency, and in particular to the literature which associates the issue of central bank transparency with monetary and fiscal policy interactions.

Since the pioneer work of Cukierman and Meltzer (1986), a large literature on central bank transparency has been developed, mostly limited to the interaction between monetary authorities and private agents. ${ }^{6}$ Most economists agree that more information is better than less and hence that openness and communication with the public are crucial for the effectiveness of monetary policy, by allowing the private sector to improve expectations and therefore to make Pareto improving decisions (Blinder, 1998; Eijffinger et al., 2000; Blinder et al., 2001; Hoeberichts et al., 2009). Adding distortions, some authors have provided counter-examples where information disclosure instead reduces the possibility for central banks to strategically use their private information, implying that greater transparency may not lead to a welfare improvement (Sorensen, 1991; Faust and Svensson, 2001; Jensen, 2002; Sibert, 2002; Westelius, 2009; Rhee and Turdaliev, 2010). In effect, according to the theory of

\footnotetext{
6 See, for a survey, Geraats (2002) and Eijffinger and van der Cruijsen (2010).
} 
the second best, removing one distortion may not lead to a more efficient allocation when other ones are present (Dincer and Eichengreen, 2007).

The empirical literature has so far yielded mixed results on whether transparency significantly affects the average level of inflation and the output gap, while it remains difficult to establish its effects on inflation and output volatility. According to Chortareas et al. (2002), disclosure of inflation forecasts reduces inflation but is not necessarily associated with higher output volatility. Demertzis and Hughes-Hallet (2007) have found that greater transparency is beneficial to inflation volatility, but has a less clear effect on output volatility and no effect on the average level of inflation and output. Dincer and Eichengreen (2007) suggest broadly favourable but relatively weak impact on inflation and output volatility.

A few studies examine the interaction between monetary and fiscal policies and put accent on the fiscal disciplining effect of central bank opacity (Hughes Hallett and Viegi, 2003; Ciccarone et al., 2007; Hefeker and Zimmer, 2011). These studies have introduced distortions induced by taxes in the supply function. Due to these distortions, the uncertainty about central bank preferences, i.e. lack of political transparency in the sense of Geraats (2002), could have a fiscal disciplining effect. Extending this literature, we introduce in this paper the issue of institutional quality into monetary and fiscal interactions with intransparency.

The remainder of the paper is structured as follows. The next section describes the model. The section after analyses the effects of central bank opacity in the benchmark model without corruption. The fourth section studies how the effects of central bank opacity are affected by corruption when the government has also a target of tolerated corruption. The fifth section considers the implications of grand corruption and some other possible extensions. The last section summarises the findings.

\section{The model}


Our analytical framework is based on models used by Alesina and Tabellini (1987), Huang and Wei (2006), and Hefeker (2010) among others. The output gap, $x$, is a positive function of surprise inflation $\pi-\pi^{e}$ (where $\pi$ is the inflation rate and $\pi^{e}$ the expected inflation rate), a negative function of the tax rate on the total revenue of firms, $\tau$, and a positive function of $\theta$, which measures the leakage of tax revenues due to corruption, with both $\theta$ and $\tau$ represented as a percentage of the national revenue:

$$
x=\alpha\left(\pi-\pi^{e}-\tau\right)+\psi \theta+u
$$

where $u$ represents a positive supply shock and is characterised by $\mathrm{E}(u)=0$ and $\operatorname{var}(\mathrm{u})=\mathrm{E}\left(u^{2}\right)=\sigma_{u}^{2}$. Generally, it is assumed that the lower the institutional quality, the greater the leakage of fiscal revenue $(\theta)$. Henceforth, we normalise $\alpha$ to unity following the literature of central bank political transparency (Hughes-Hallett and Viegi, 2003; Ciccarone et al., 2007; Demertzis and Hughes Hallet, 2007). ${ }^{7}$

Equation (1) stipulates that taxes have systematically non-neutral effects on the output gap and are distortionary in the sense of depressing the output gap and thus employment. As to the effect of corruption on the supply function, we work with both 'sanding-the-wheels' and 'greasing-the-wheels' hypotheses. Under the first hypothesis, the potentially positive effect of corruption on output is more than counterbalanced by its negative effect, and vice versa under the second one. In the early literature on corruption, under the 'efficient corruption' hypothesis, corruption is considered as a way to compensate the distortion caused by the burden of distortionary taxation and could thus be viewed as 'grease money' to

\footnotetext{
7 The unitary inflation elasticity is usually assumed in this literature because uncertainty about the inflation stabilisation parameter increases the expected response of inflation to supply shocks, and amplifies the volatility of inflation but limits the volatility of output, while the effects could be inversed under uncertainty about the output stabilisation parameter (Geerats, 2002). To avoid that expected level and volatility of inflation could be sensitive to the arbitrary specification of uncertainty about one or the other parameter attached to the central bank's objectives, the inflation elasticity of the supply curve must be normalised to unity and the preference weights must be chosen so as to have their sum equal to one.
} 
lubricate the squeaky wheels of a rigid administration (Leff, 1964). Baretto (2000) has pointed out that the efficiency-enhancing effect of corruption results from the fact that corruption can reduce bureaucratic inefficiency. Coppier and Michetti (2006) have shown that more corruption could be associated with more production, in accordance with some empirical evidence provided by Coppier and Piga (2004). However, the 'efficient corruption' hypothesis is contestable (Kaufmann and Wei, 1999; Aidt, 2003; Méon and Sekkat, 2005). The negative effect of corruption is due to its adverse effect on the investment of firms (Mauro, 1995; Campos et al., 1999), the efficiency of public expenditures (Del Monte and Papagni, 2001), the governance (Blackburn and Forgues-Puccio, 2007) and the factor requirements of firms (Dal Bó and Rossi, 2007). The recent consensus is that the 'greasing-the-wheels' hypothesis could be verified only in countries where institutions are ineffective (Aidt, 2009; Méon and Weill, 2010; De Vual and Ebben, 2011).

To finance public expenditures represented as a percentage of national revenue, $g$, the government levies an output tax at the rate $\tau$, which is reduced by corruption $\theta$. The government's budget constraint is

$$
g=\tau-\theta
$$

As in Alesina and Tabellini (1987), Huang and Wei (2006), Wu (2008), and Hefeker (2010), we assume a balanced budget in the sense that there is no debt financing of government's budget deficit. ${ }^{8}$ We diverge however from the above studies by simplifying further the budget constraint in assuming that there is no monetary financing of the budget deficit in (2), i.e. the absence of $\pi$ representing the seigniorage revenue. The inclusion of the latter would make the transmission mechanism of monetary policy extremely complex in the

\footnotetext{
8 An alternative assumption is that the government can temporarily have budget deficits. Some authors such as Agell et al. (1996), Demertzis et al. (2004), and Bohn (2013) have shown that a balanced budget objective can be included in the government's loss function. This can be explained by the fact that on the one hand, the government experiences disutility from a budget deficit because the latter entails a political cost, and on the other hand it is concerned with the redistribution of consumption possibilities over time (across generations) that are associated with an unbalanced budget.
} 
presence of central bank intransparency, rendering impossible to obtain clear-cut analytical results.

The government aims to simultaneously stabilise inflation and the output gap around zero and public expenditures around their target $\bar{g}$. The introduction of an expenditure target could reflect the desire of being re-elected or other demands from interest groups that the government must satisfy.

Moreover, we assume that the government is concerned with stabilising corruption and minimises the political costs arising from deviations from a given target of corruption $(\bar{\theta})$ by controlling its effective level $(\theta)$. In effect, increasing corruption might result in protest from the population, lower foreign investment or less support from international financial organisations. Corruption fighting, through more control of public servants, reduction of the influence of interest groups and rent-seeking, and creation of better institutions like setting up independent courts and improving public administration, implies a cost for the government. On the other hand, a reduction in corruption leads to alienation of former beneficiaries of corruption, such as interest groups or bureaucrats that resist corruption fighting. Due to the personal or political costs of fighting corruption, deviations of the level of corruption in either direction from $\bar{\theta}$ are costly (Hefeker, 2010). ${ }^{9}$

The government's objective function is given by

$$
L^{G}=\frac{1}{2} \mathrm{E}\left[\delta_{1} \pi^{2}+x^{2}+\delta_{2}(g-\bar{g})^{2}+\delta_{3}(\theta-\bar{\theta})^{2}\right]
$$

where $\mathrm{E}$ is the operator of mathematical expectations. The loss function (3) represents a benevolent government whose leaders do not benefit from corruption but suffer from its political costs. This formulation does not take account of grand corruption considered in Bohn (2013), who in contrast, disregards political costs due to corruption. To understand the

\footnotetext{
${ }^{9}$ We will consider in Section 5 the implications of including the financial costs of corruption fighting in the budget constraint.
} 
implications of a non-benevolent government, we will examine in Section 5 the interactions between monetary and fiscal policies in relation to grand corruption and central bank intransparency.

Following Rogoff (1985), we assume that the government, while keeping control of its fiscal instrument, delegates the conduct of monetary policy to an independent central bank. This institutional design is generally adopted by recent studies on fiscal and monetary policy interactions in the presence of corruption (e.g., Huang and Wei, 2006; Hefeker, 2010; Bohn, 2013). Such an assumption reflects well the great progress that emerging market economies have done in promoting central bank independence since the 1980s (Arnone et al., 2009). We assume that the central bank sets its policy to minimise the following loss function:

$$
L^{C B}=\frac{1}{2}\left[(\mu-\varepsilon) \pi^{2}+(1+\varepsilon) x^{2}\right], \quad \mu>0
$$

where parameter $\mu$ is the relative weight that the central bank assigns to the inflation target and it might be different from that of the government.

The transparency issue is introduced by assuming that the weights assigned by the central bank to inflation and output-gap targets are not perfectly predictable by the government and the private sector. Following Ciccarone et al. (2007), the imperfect disclosure of information about central bank preferences is represented by the fact that $\varepsilon$ is stochastic. Thus, uncertainty affects both preference parameters in (4). This specification is adopted to avoid the arbitrary effects of central bank preference uncertainty on monetary policy underlined by Beetsma and Jensen (2003). They have shown that the results of Eijffinger et al. (2000), who assume that uncertainty is associated with the weight assigned to inflation stabilisation, could be inversed if uncertainty is associated with the weight assigned to output stabilisation. The 
approach of Ciccarone et al. (2007) provides an elegant way to avoid that a slight change in the uncertainty specification leads central bank opacity to have radically different effects. ${ }^{10}$

The density function of $\varepsilon$ is characterised by $\mathrm{E}(\varepsilon)=0, \operatorname{var}(\varepsilon)=\mathrm{E}\left(\varepsilon^{2}\right)=\sigma_{\varepsilon}^{2}$ and $\varepsilon \in[-1, \mu]$. The variance $\sigma_{\varepsilon}^{2}$ represents the degree of opacity about central bank preferences. As the random variable $\varepsilon$ takes values in a compact set and has an expected value equal to zero, $\sigma_{\varepsilon}^{2}$ must have a well-defined upper bound, i.e. $\sigma_{\varepsilon}^{2} \in[0, \mu] .{ }^{11}$ When $\sigma_{\varepsilon}^{2}=0$, the central bank is fully transparent. Furthermore, we assume that shocks $\varepsilon$ and $u$ are independent.

Fiscal and monetary authorities play a Stackelberg game with the government as the leader. The timing of the game is as follows. First, the private sector forms rational expectations about inflation and sets wages, then the government sets the tax rate and the level of corruption before the realisation of supply shocks, and finally the central bank makes the monetary policy decision to attain the inflation target. The model is solved by backward induction.

\section{The benchmark equilibrium}

To better understand how corruption affects the interactions between monetary policy transparency and fiscal policy decisions, we consider here the benchmark model where the issue of corruption is absent. ${ }^{12} \mathrm{We}$ eliminate $\theta$ in equations (1)-(3) while keeping equation (4) unchanged. Solving the model yields the equilibrium solutions (Appendix A.2):

$$
\pi=\frac{1+\varepsilon}{\varepsilon-\mu} x=\frac{(1+\varepsilon)(1+\mu) \delta_{2} \bar{g}}{A}-\frac{(1+\varepsilon)(1+\mu) \delta_{2} u}{A+(1+\mu) \delta_{2}}
$$

\footnotetext{
10 An alternative is to choose preference weights so that their sum is equal to one (Geraats, 2002).

11 See Ciccarone et al. (2007) for the proof.

12 The benchmark model is similar to that of Hefeker and Zimmer (2011) except for stochastic supply shocks.
} 


$$
\tau=g=\frac{\mu(1+\mu) \delta_{2} \bar{g}}{A}+\frac{\left[\delta_{1}+\mu^{2}+\left(1+\delta_{1}\right) \sigma_{\varepsilon}^{2}\right] u}{A+(1+\mu) \delta_{2}} .
$$

where $A=\delta_{1}+\mu^{2}+\mu(1+\mu) \delta_{2}+\left(1+\delta_{1}\right) \sigma_{\varepsilon}^{2}$.

In the above solutions, the denominators increase with $\sigma_{\varepsilon}^{2}$, while the numerators are invariant with $\sigma_{\varepsilon}^{2}$ except the one associated with supply shocks in (6).

Denote respectively by $u_{\max }(>0)$ and $u_{\min }(<0)$ the maximal and minimal values for the supply shock. To ensure that the tax rate and public expenditures are both strictly positive, we impose that $\bar{g}>-\frac{\left[\delta_{1}+\mu^{2}+\left(1+\delta_{1}\right) \sigma_{\varepsilon}^{2}\right] A}{\mu(1+\mu) \delta_{2}\left[A+(1+\mu) \delta_{2}\right]} u_{\min } \cdot 13$

Putting aside the effects of supply shocks, due to distortionary taxes, the equilibrium solutions depend on the target of public expenditures. For a given $\bar{g}$, central bank opacity has a disciplining effect through the inflation expectations channel. In effect, an increase in opacity $\sigma_{\varepsilon}^{2}$ leads the government to reduce taxes and public expenditures, inducing hence lower inflation and a higher output gap. This is explained by the fact that the effect of distortionary taxes levied to finance public expenditures implies higher expected and current inflation, and lower output. The fiscal authority perceives that marginal costs associated with higher taxes are increasing in the degree of uncertainty about central bank preferences. In accordance with Brainard's (1967) conservatism principle, opacity has hence a 'disciplining effect' in the sense that the government will adopt a less aggressive fiscal policy with lower public expenditures and taxes. This stance of fiscal policy leads to lower inflation and a higher output gap at the cost of a larger deviation of public expenditures from their target.

Solutions (5)-(6) allow us to assess the interactions between the effects of opacity and those of supply shocks. Simple algebra shows that opacity moderates the effects of supply shocks on inflation and the output gap but amplifies the variations of the tax rate and public

\footnotetext{
13 This condition is obtained using (6) by imposing that $\tau=g>0$ for all supply shocks.
} 
expenditures. The underlying mechanism is governed by the interplay of two effects of opacity on the decision of the government. First, the disciplining effect always reduces the incentive for the government to increase the tax rate, leading to a moderated reaction of inflation and the output gap to the supply shock. Second, opacity increases the relative weight that the government puts on inflation and output stabilisation with respect to that of public expenditures. The government has thus incentive to increase the reaction of the tax rate to the supply shock to compensate the effect of opacity on social welfare. ${ }^{14}$ As to the tax rate and public expenditures, the second effect dominates the disciplining effect while the inverse is true concerning inflation and the output gap.

Using (5), the volatility of inflation and that of the output gap are calculated as

$$
\operatorname{var}(\pi)=\operatorname{var}(x)=\frac{\left[\delta_{2}(1+\mu) \bar{g}\right]^{2} \sigma_{\varepsilon}^{2}}{A^{2}}+\frac{(1+\mu)^{2} \delta_{2}^{2} \sigma_{\varepsilon}^{2} \sigma_{u}^{2}}{\left[A+(1+\mu) \delta_{2}\right]^{2}}
$$

Since numerators and denominators of (7) are increasing in $\sigma_{\varepsilon}^{2}$, the effects of central bank opacity depend on the preference parameters of the central bank and the government as well as the initial degree of opacity. Opacity triggers two opposing effects on the volatility of inflation and the output gap in relation to the target of public expenditures. The positive direct effect of opacity through the policy channel (i.e., the effect of preference shocks on inflation and the output gap) can be counterbalanced by the fiscal disciplining effect if the initial degree of opacity is sufficiently high, i.e. $\sigma_{\varepsilon}^{2}>\frac{\delta_{1}+\mu^{2}+\delta_{2} \mu(1+\mu)}{1+\delta_{1}}$ and vice versa. Taking account of the upper bound on $\sigma_{\varepsilon}^{2}$ found by Ciccarone et al. (2007), i.e. $\sigma_{\varepsilon}^{2}<\mu$, we find that

\footnotetext{
14 Using (1) for $\psi=0$ and $\alpha=1$, and the central bank's reaction function $\pi=\frac{(1+\varepsilon)\left(\tau+\pi^{e}-u\right)}{1+\mu}$ to obtain $x=\frac{(\varepsilon-\mu)\left(\tau+\pi^{e}-u\right)}{1+\mu}$, the government's loss function could be rewritten as $L^{G}=\frac{1}{2}\left[\Theta\left(\tau+\pi^{e}-u\right)^{2}+\delta_{2}(\tau-\bar{g})^{2}\right]$, where $\Theta \equiv \mathrm{E}\left[\frac{\delta_{1}(1+\varepsilon)^{2}+(\varepsilon-\mu)^{2}}{(1+\mu)^{2}}\right] \cong \frac{\delta_{1}+\mu^{2}+\left(1+\delta_{1}\right) \sigma_{\varepsilon}^{2}}{(1+\mu)^{2}}$, i.e., a second-order Taylor approximation. The term $\Theta\left(\tau+\pi^{e}-u\right)^{2}$ is an equivalent expression for $\mathrm{E}\left(\delta_{1} \pi^{2}+x^{2}\right)$. Given that $\Theta$ is a positive function of $\sigma_{\varepsilon}^{2}, L^{G}$ is increasing in opacity.
} 
$\sigma_{\varepsilon}^{2}>\frac{\delta_{1}+\mu^{2}+\delta_{2} \mu(1+\mu)}{1+\delta_{1}}$ is true only when $\frac{\delta_{1}+\mu^{2}+\delta_{2} \mu(1+\mu)}{1+\delta_{1}}<\mu$ or $\delta_{2}<\frac{\mu\left(1+\delta_{1}\right)-\left(\delta_{1}+\mu^{2}\right)}{\mu(1+\mu)}$. In other words, the fiscal disciplining effect is more likely to dominate the direct effect when the government is less concerned with the public expenditures deviations (smaller $\delta_{2}$ ). If $\delta_{2}$ is large, the direct effect always dominates the fiscal disciplining effect.

Opacity moderates the contribution of the variance of supply shocks to the volatility of inflation and the output gap if $\sigma_{\varepsilon}^{2}>\frac{\delta_{1}+\mu^{2}+\delta_{2}(1+\mu)^{2}}{1+\delta_{1}}$ and vice versa. Given that $\sigma_{\varepsilon}^{2}<\mu$, it is straightforward to show that $\sigma_{\varepsilon}^{2}>\frac{\delta_{1}+\mu^{2}+\delta_{2}(1+\mu)^{2}}{1+\delta_{1}}$ is true only when $\frac{\delta_{1}+\mu^{2}+(1+\mu)^{2} \delta_{2}}{1+\delta_{1}}<\mu$ or $\delta_{2}<\frac{\mu\left(1+\delta_{1}\right)-\left(\delta_{1}+\mu^{2}\right)}{(1+\mu)^{2}}$.

\section{The effects of opacity on the equilibrium with tolerated corruption}

We present now the full model where corruption affects the supply function as well as the government budget constraint. We examine first the case where the benevolent government does not stabilise corruption around a target of tolerated corruption, and then the case where it desires to stabilise corruption around such a target.

The equilibrium solution of the model constituted of (1)-(4) is given by (Appendix A.1)

$$
\begin{aligned}
& \pi=\frac{1+\varepsilon}{\varepsilon-\mu} x=\frac{(1+\varepsilon) \delta_{2} \delta_{3}[\bar{g}-(\psi-1) \bar{\theta}]}{B}-\frac{(1+\varepsilon) \delta_{2} \delta_{3} u}{B+\delta_{2} \delta_{3}}, \\
& \tau=\frac{\left[(1+\mu)(\psi-1) \psi \Theta+\mu \delta_{3}\right] \delta_{2} \bar{g}+\left[(1+\mu) \psi \Theta+\mu \delta_{2}\right] \delta_{3} \bar{\theta}}{B}-\frac{\Theta(1+\mu)\left[(\psi-1) \delta_{2}-\delta_{3}\right] u}{B+\delta_{2} \delta_{3}}, \\
& \theta=\frac{(1+\mu)(\psi-1) \Theta \delta_{2} \bar{g}+\left[(1+\mu) \Theta+\mu \delta_{2}\right] \delta_{3} \bar{\theta}}{B}-\frac{\delta_{2}(1+\mu)(\psi-1) \Theta u}{B+\delta_{2} \delta_{3}},
\end{aligned}
$$

where $B=\mu \delta_{2} \delta_{3}+(1+\mu) \Theta \delta_{3}+(1+\mu)(\psi-1)^{2} \delta_{2} \Theta$. 
In the following, we examine first the cases where an interior equilibrium solution for $g>0$ and $\theta>0$ exists. Then, we consider the equilibrium solution where the optimal value of $\theta$ is negative. Since a negative level of corruption is also accompanied by a negative tax rate, such an equilibrium solution has little sense in practice. To avoid this, we assume that $\theta \geq 0$

\subsection{The equilibrium without a government target for corruption}

Before considering the role played by corruption stabilisation in the transmission of the effects of opacity, it is instructive to study the equilibrium where the government ignores the political costs of corruption as in Huang and Wei (2006) and Bohn (2013). This implies that the government can affect corruption in either direction without political costs and the society is indifferent to any level of corruption. ${ }^{15}$

\section{Interior solutions}

Taking the limit of (8)-(10) by imposing $\delta_{3}=0$ yields:

$$
\pi=x=0, \quad \tau=\frac{\psi \bar{g}-u}{\psi-1}, \quad \theta=\frac{\bar{g}-u}{\psi-1} .
$$

Public expenditures generally represent a large percentage of national revenue. Thus, it is reasonable to assume that $\bar{g}-u_{\max }>0$. Given that $\tau$ and $\theta$ cannot be smaller than zero, the above solutions indicate that we must have $\psi>1$ for the interior equilibrium solution to exist. For $\delta_{3}=0$, the government does not fight corruption. This is the case where the government has very weak institutions and only a strong 'greasing-the-wheels' effect of corruption on the production (i.e., $\psi>1$ ) is compatible with a positive average value for $g$ and $\tau$, and a nonnegative value for $\theta$ in the equilibrium.

\footnotetext{
15 Bohn (2013), instead of considering any political costs induced by deviations of corruption from the level tolerated by the society, takes account of benefits from grand corruption.
} 
Proposition 1a. When the government does not care about the stabilisation of corruption, it can fully neutralise the effects of distortionary taxes and supply shocks on output if $\psi>1$. Therefore, the equilibrium level and volatility of the tax rate, corruption, inflation and the output gap are independent of central bank preferences and hence not affected by central bank opacity.

Proof. It follows straightforwardly from (11).

The results summarised in Proposition 1a are easy to interpret. In the benchmark model of Section 3 without corruption, $\tau$ cannot be fixed in a way to completely neutralise the effects of central bank's opacity on the social welfare. If the government sets $\tau_{t}=-\pi_{t}^{e}+u$ to neutralise the effects of opacity on the social welfare, it suffers from high marginal costs due to insufficient public expenditures. Hence, the optimal tax rate depends on the degree of opacity.

In the present case, despite the effects of corruption on the supply function and the budget constraint, the government does not desire to stabilise corruption around a predetermined target. The constraint (2) shows that the government has two free instruments (i.e., $\tau$ and $\theta$ ) and one fiscal policy objective to attain (i.e., $g$ ). The government can therefore use these two instruments to stabilise public expenditures while neutralising the effects of opacity on fiscal decisions, and completely counterbalancing the effects of distortionary taxes and supply shocks on the output.

Proposition 1, suggesting that the equilibrium solutions are independent of monetary policy decisions and thus central bank opacity, is in line with the result highlighted by Huang and Wei (2006). By adopting a government loss function identical to that used in this 
subsection, they suggest that the optimal degree of conservatism is equal to zero and in this respect the role of an independent and transparent central banker is insignificant.

\section{Corner solutions}

If the 'greasing-the-wheels' effect is moderately positive, $0<\psi<1$, or the 'sanding-thewheels' effect prevails (i.e. $\psi<0$ ), solutions given by (11) imply negative average values for $\tau, g$ and $\theta$. Given that it is impossible to have $\theta<0$ and an incompressible level for corruption is not introduced in the model, the government will just set $\theta=0$. Solving the model for $\theta=0$ leads to solutions identical to those of the benchmark model (see Appendix A.1).

Proposition 1b. When the government does not care about the stabilisation of corruption, it cannot neutralise the effects of distortionary taxes on output even by setting $\theta=0$ if the effect of corruption on the supply function is sufficiently small, i.e. $\psi<1$. The equilibrium level and volatility of the tax rate, corruption, the inflation rate and the output gap depend on central bank preferences and therefore they are affected by central bank opacity as in the benchmark equilibrium.

The government would prefer a larger amount of public expenditures to be financed through taxes and hence would aggressively fight against corruption so that the latter is reduced to zero. The government has a great incentive to fight corruption either when the 'greasing-the-wheels' effect of corruption on the supply function is inferior to that of a decrease in taxes or when corruption has a 'sanding-the-wheels' effect. Since the choice of the tax rate is not anymore affected by that of corruption at the zero lower bound for corruption, the government loses one free instrument and has thus only one free instrument left at its 
disposal to make the best trade-off between higher social welfare costs induced by central bank opacity and those induced by not attaining the target of public expenditures. As in the benchmark case, the optimal tax rate is set at a lower level under opacity than under full transparency, at the price of lower public expenditures and hence greater deviations of the latter from their target.

\subsection{The equilibrium with a government target for corruption}

When the government takes into account political costs of corruption, i.e. $\delta_{3}>0$, according to (9)-(10), the existence of interior solutions for $\theta$ and $g$, i.e., $\theta, g>0$, depends on the hypothesis about the effect of corruption on the production as well as other parameters of the model.

\section{The interior solutions}

When the 'greasing-the-wheels' effect is moderate (i.e., $0<\psi<1$ ) or the 'sanding-thewheels' effect prevails (i.e., $\psi<0$ ), to ensure that $\theta, g>0$, we must have:

$$
\Phi_{1}<\bar{g}<\Phi_{2},
$$

where $\Phi_{1} \equiv \frac{\delta_{3} \bar{\theta} \Theta(1-\psi)(1+\mu)\left(B+\delta_{2} \delta_{3}\right)-(1+\mu) \delta_{3} \Theta B u_{\min }}{\left(B+\delta_{2} \delta_{3}\right)\left[B-(1+\mu) \Theta \delta_{3}\right]}$ and $\Phi_{2} \equiv \frac{B u_{\min }}{B+\delta_{2} \delta_{3}}+\frac{\delta_{3} \bar{\theta}\left[(1+\mu) \Theta+\mu \delta_{2}\right]}{\delta_{2} \Theta(1+\mu)(1-\psi)} \cdot{ }^{16}$

To ensure that condition (12) is valid, we must have $\Phi_{2}-\Phi_{1}>0$. The latter yields:

$$
u_{\min }>-\frac{\left(B+\delta_{2} \delta_{3}\right) \mu \delta_{3} \bar{\theta}}{(1-\psi)(1+\mu) \Theta B} \equiv \Omega .
$$

We remark that if the weight assigned to the government's objective of corruption fighting is zero $\left(\delta_{3}=0\right)$ for a positive target level of corruption $\bar{\theta}$, condition (13) will not be valid except when $u_{\min }>0$. Since demand shocks are either positive or negative, we would

\footnotetext{
${ }^{16}$ Using (9) and (10), we obtain $\Phi_{1}<\bar{g}$ by imposing $\tau-\theta>0$ for all values of $\psi$, and $\bar{g}<\Phi_{2}$ and $\bar{g}>\Phi_{2}^{\prime}$ by imposing $\theta>0$ for $\psi<1$ and $\psi>1$ respectively.
} 
generally have $u_{\min }<0$. This means that the interior solution exists for $\psi<1$, i.e. corruption has week positive or negative effect on the production, only if $\delta_{3}$ is sufficiently large such that condition (13) is always verified for given $u_{\min }$.

In the case where the 'greasing-the-wheels' effect is very strong, $\psi>1$, we must have $\bar{g}>\max \left\{\Phi_{1}, \Phi_{2}^{\prime}\right\}$, where $\Phi_{2}^{\prime} \equiv \frac{B u_{\max }}{B+\delta_{2} \delta_{3}}+\frac{\delta_{3} \bar{\theta}\left[(1+\mu) \Theta+\mu \delta_{2}\right]}{\delta_{2} \Theta(1+\mu)(1-\psi)}$, to ensure that $\theta, g>0$. Given that $\Phi_{1}$ is always negative for $\psi>1$, the previous condition becomes

$$
\bar{g}>\Phi_{2}^{\prime}
$$

Under the condition (14), the tax rate and corruption are positive at the equilibrium. Denote $\psi_{\min }=\min \left\{1+\frac{\delta_{3}}{\delta_{2}} ; 1+\frac{\bar{g}}{\bar{\theta}}\right\}$ and $\psi_{\max }=\max \left\{1+\frac{\delta_{3}}{\delta_{2}} ; 1+\frac{\bar{g}}{\bar{\theta}}\right\}$.

Proposition 2a. When the government cares about the stabilisation of corruption and an interior equilibrium solution exists, an increase in central bank opacity induces lower inflation, tax rate, public expenditures and corruption but higher output in the absence of supply shock if the effect of corruption on the supply function is negative i.e. $\psi<0$. It induces lower inflation and public expenditures and higher output if the positive effect of corruption on the supply function is not too large, i.e. $0<\psi<1+\frac{\bar{g}}{\bar{\theta}}$, but inverse effects on these variables if $\psi>1+\frac{\bar{g}}{\bar{\theta}}$. It induces lower corruption if $0<\psi<1$ or $\psi>1+\frac{\bar{g}}{\bar{\theta}}$ and a lower tax rate if $0<\psi<\psi_{\min }$ or $\psi>\psi_{\max }$, but higher corruption if $1<\psi<1+\frac{\bar{g}}{\bar{\theta}}$ and a higher tax rate if $\psi_{\min }<\psi<\psi_{\max }$.

Proof. See Appendix B.

The results reported in Proposition 2a are explained by contradictory incentives faced by the government. First, the government still abides by the fiscal discipline imposed by opacity. 
Second, the government's decision to increase or not corruption must be made taking into account the complex trade-offs induced by the effect of corruption on the supply function and the government's budget constraint, and hence social welfare.

Under the 'sanding-the-wheels' hypothesis, which is verified for most developed and developing countries with reasonably efficient institutions, opacity has similar effects as in the benchmark model. Moreover, the 'sanding-the-wheels' hypothesis actually strengthens the fiscal disciplining effect of opacity since the more $\psi$ is negative, the stronger the effects of opacity on inflation, output, tax rate, corruption and public expenditures. In effect, the government would have a stronger incentive to reduce corruption when the latter is more harmful. At the same time, in response to central bank opacity, the government would reduce public expenditures and could afford thus a lower tax rate, implying that the tax rate decreases more than corruption to ensure that the budget is balanced.

Considering the 'greasing-the-wheels' hypothesis, we distinguish three possible scenarios: 1) If $\psi$ moderately positive, the fiscal disciplining effect dominates and consequently intransparency is useful as a macroeconomic stabilisation device while the government increases corruption for its disinflationary effect. 2) When $\psi$ is largely positive, to avoid the destabilising effect of increasing corruption, i.e. inducing a too important decrease (increase) in inflation (the output gap) and public expenditures, the government prefers reducing corruption to obtain higher inflation. Together with the fiscal disciplining effect, this leads to a decrease in the tax rate, the output gap and corruption but results to an increase in inflation. 3) When $\psi$ is at an intermediate level, opacity induces the government to increase the tax rate so that it can vary more the level of corruption to stabilise inflation and the output gap and public expenditures. If $\frac{\delta_{3}}{\delta_{2}}<\frac{\bar{g}}{\bar{\theta}}$, inflation and the output gap and public expenditures evolve as in the first scenario. If the previous condition is reversed, the second scenario will prevail. 
Proposition 2b. When the government cares about the stabilisation of corruption and an interior equilibrium solution exists, an increase in central bank opacity attenuates the effects of supply shocks on inflation and the output gap independently of the value of $\psi$. More opacity amplifies the effects of supply shocks on the tax rate (corruption) if $\psi>1+\frac{\delta_{3}}{\delta_{2}}$ ( if $\psi>1$ respectively) and vice versa.

Proof. See Appendix C.

In comparison with the case considered in subsection 4.1, the government with an objective of stabilising corruption has not enough free instruments to neutralise the effects of supply shocks. Whatever the effect of corruption on the supply function ('sanding- or greasing-the-wheels'), opacity attenuates the reactions of inflation and the output gap to supply shocks because the government has to reduce the volatility of inflation and the output gap to compensate the detrimental effect of opacity on the social welfare. As to the tax rate, public expenditures and corruption, the mechanism underlying the interactions between the effects of opacity and the effects of supply shocks in the benchmark model is again effective. Here, the disciplining effect of opacity must be gauged in relation to a second channel through which opacity could affect macroeconomic variables, i.e. opacity increases the relative weight that the government puts on inflation and output stabilisation with respect to other objectives, and hence the government's incentive to increase the reaction of the tax rate and therefore that of public expenditures and corruption. If the 'greasing-the-wheels' effect of corruption is small or when 'sanding-the-wheels' effect prevails, the fiscal disciplining effect on the tax rate dominates the effect of opacity through the second channel. The opposite result is obtained when the 'greasing-the-wheels' effect is sufficiently large. Thus, the government, in 
response to a negative supply shock, increases the tax rate, corruption and public expenditures, leading to lower inflation and a higher output gap.

The volatility of inflation and the output gap is obtained using (8) as:

$$
\operatorname{var}(\pi)=\operatorname{var}(x)=\frac{\delta_{2}^{2} \delta_{3}^{2}[\bar{g}+(1-\psi) \bar{\theta}]^{2}}{B^{2}} \sigma_{\varepsilon}^{2}+\frac{\delta_{2}^{2} \delta_{3}^{2}}{\left(B+\delta_{2} \delta_{3}\right)^{2}} \sigma_{u}^{2} .
$$

Proposition 3. When the government cares about the stabilisation of corruption, an increase in central bank opacity reduces both inflation and output-gap volatility due to supply shocks. In the absence of supply shocks, it reduces both inflation and output-gap volatility if the initial degree of opacity is sufficiently high, i.e., $\sigma_{\varepsilon}^{2}>\frac{(1+\mu) \mu \delta_{2} \delta_{3}}{\left(1+\delta_{1}\right)\left[\delta_{3}+(\psi-1)^{2} \delta_{2}\right]}+\frac{\delta_{1}+\mu^{2}}{1+\delta_{1}}$.

\section{Proof. See Appendix D.}

When the government has two objectives, i.e. stabilisation of public expenditures and corruption, and two free instruments, it cannot neutralise the effects of opacity on the volatility of inflation and the output gap. The fiscal disciplining effect of opacity dominates its direct effect only if the initial degree of opacity is sufficiently high.

\section{The corner solutions}

In the cases where the 'greasing-the-wheels' effect is moderately positive, $0<\psi<1$, and the 'sanding-the-wheels' effect prevails (i.e. $\psi<0$ ), the solution of $\theta$ given in (10) suggests that $\theta<0$ if $\bar{g}>\Phi_{2}$. In the case where the 'greasing-the-wheels' effect is very strong, $\psi>1$, if the condition (14) is reversed, i.e. $\bar{g}<\Phi_{2}^{\prime}$, we would also have $\theta<0$. Given that we cannot reduce corruption to a negative level, we impose $\theta=0$ so that the solutions of $\pi, x, \tau$ and $g$ are identical to the benchmark solutions (5)-(6) (see Appendix A.1). 
Proposition 4. The government, caring about the stabilisation of corruption, sets corruption to zero if the effect of corruption on the supply function is sufficiently small (i.e., $\psi<1$ ) and the target of public expenditures is relatively high (i.e., $\bar{g}>\Phi_{2}$ ). It makes the same decision if the effect of corruption is sufficiently large (i.e., $\psi>1$ ) and the target of public expenditures is sufficiently low (i.e., $\bar{g}<\Phi_{2}^{\prime}$ ). The equilibrium level and volatility of the tax rate, the inflation rate and the output gap are affected by central bank opacity as in the benchmark equilibrium.

It is easy to see from (10) that, in both cases of 'sanding-the-wheels' and moderate 'greasing-the-wheels' effect, the government could reduce corruption to its zero lower bound if $\bar{g}>\Phi_{2}$. This condition could be easily verified if the target of the latter not too high, and the weight assigned to the stabilisation of public expenditures and the objective of corruption fighting respectively as well as the target of corruption were relatively low. When the 'greasing-the-wheels' effect is large, the necessary condition for $\theta<0$ is $\bar{g}<\Phi_{2}^{\prime}$ according to (10). Under this condition, a corner solution for corruption exists but has a small probability since it is only possible in the presence of sufficiently large positive supply shocks. The latter incite the government to reduce corruption to zero as a way of limiting the variations of output and inflation.

By setting $\theta=0$, the government will have only one free policy instrument, i.e. the tax rate. With one remaining free instrument to deal with the trade-offs between three other objectives, the government makes exactly the same decisions as in the benchmark model.

Denote by $\Gamma_{1} \equiv \frac{\delta_{2} \mu(1+\mu)+\mu^{2}+\delta_{1}}{1+\delta_{1}}$ and $\Gamma_{2} \equiv \frac{(1+\mu) \mu \delta_{2} \delta_{3}}{\left(1+\delta_{1}\right)\left[\delta_{3}+(\psi-1)^{2} \delta_{2}\right]}+\frac{\delta_{1}+\mu^{2}}{1+\delta_{1}}$. We summarise the effect of opacity in the absence of supply shocks in Table 1. 
Table 1: The fiscal disciplining effect of opacity when supply shocks are absent

\begin{tabular}{|c|c|c|c|c|c|c|c|c|c|}
\hline \multirow{3}{*}{$\begin{array}{l}\text { Fiscal } \\
\text { disciplining } \\
\text { effect of } \\
\text { opacity }\end{array}$} & \multirow{3}{*}{$\begin{array}{l}\text { Benchmark } \\
\text { model } \\
(\psi=0, \\
\left.\delta_{3}=0\right)\end{array}$} & \multicolumn{4}{|c|}{ No target of corruption fighting $\left(\delta_{3}=0\right)$} & \multicolumn{4}{|c|}{ With target of corruption fighting $\left(\delta_{3}>0\right)$} \\
\hline & & \multicolumn{2}{|c|}{$\begin{array}{c}\text { Sanding-the-wheels } \\
(\psi<0)\end{array}$} & \multicolumn{2}{|c|}{ Greasing-the-wheels } & \multicolumn{2}{|c|}{$\begin{array}{l}\text { Sanding-the-wheels } \\
(\psi<0)\end{array}$} & \multicolumn{2}{|c|}{$\begin{array}{c}\text { Greasing-the-wheels } \\
(\psi>0)\end{array}$} \\
\hline & & & & $0<\psi<1$ & $\psi>1$ & $\Phi_{1}<\bar{g}<\Phi_{2}$ & $\bar{g}>\Phi_{2}$ & $\bar{g}>\Phi_{2}^{\prime}$ & $\bar{g}<\Phi_{2}^{\prime}$ \\
\hline$\frac{\partial \pi}{\partial \sigma_{\varepsilon}^{2}}<0$ & Yes & * & * & $*$ & No & Yes & * & Yes if $\psi<1+\frac{\bar{g}}{\bar{\theta}}$ & $*$ \\
\hline$\frac{\partial x}{\partial \sigma_{\varepsilon}^{2}}>0$ & Yes & * & $*$ & $*$ & No & Yes & $*$ & Yes if $\psi<1+\frac{\bar{g}}{\bar{\theta}}$ & $*$ \\
\hline$\frac{\partial \theta}{\partial \sigma_{\varepsilon}^{2}}<0$ & $\theta=0$ & * & $*$ & $*$ & No & Yes & * & $\begin{array}{l}\text { Yes if } \psi<1 \text { or } \\
\psi>1+\frac{\bar{g}}{\bar{\theta}}\end{array}$ & $*$ \\
\hline$\frac{\partial g}{\partial \sigma_{\varepsilon}^{2}}<0$ & Yes & $*$ & $*$ & $*$ & No & Yes & $*$ & Yes if $\psi<1+\frac{\bar{g}}{\bar{\theta}}$ & $*$ \\
\hline$\frac{\partial \tau}{\partial \sigma_{\varepsilon}^{2}}<0$ & Yes & $*$ & $*$ & $*$ & No & Yes & $*$ & $\begin{array}{l}\text { Yes if } \psi<\psi_{\min } \\
\text { or } \psi>\psi_{\max }\end{array}$ & $*$ \\
\hline$\frac{\partial \sigma_{\pi, x}^{2}}{\partial \sigma_{\varepsilon}^{2}}<0$ & $\begin{array}{l}\text { Yes } \\
\text { if } \sigma_{\varepsilon}^{2}>\Gamma_{1}\end{array}$ & * & $*$ & $*$ & No & $\begin{array}{l}\text { Yes } \\
\text { if } \sigma_{\varepsilon}^{2}>\Gamma_{2}\end{array}$ & $*$ & $\begin{array}{l}\text { Yes } \\
\text { if } \sigma_{\varepsilon}^{2}>\Gamma_{2}\end{array}$ & $*$ \\
\hline
\end{tabular}

* Corner solutions identical to those of the benchmark model.

\section{The implications of grand corruption and other extensions}

Our previous results are obtained with a government loss function exhibiting benevolent behaviour, a budget constraint excluding seigniorage revenue, debt-financing and costs of corruption fighting, while assuming that the underlying interactions between monetary and fiscal authorities are characterised by a Stackelberg game. In what follows, we verify the robustness of our results by analysing how they are affected by adopting alternative assumptions.

\subsection{The effects of grand corruption}

Assume that the government embraces grand corruption of the kind considered in Bohn (2013) such that its loss function becomes:

$$
L^{G}=\frac{1}{2} \mathrm{E}\left[\delta_{1} \pi^{2}+x^{2}+\delta_{2}(g-\bar{g})^{2}+\delta_{3}(\theta-\bar{\theta})^{2}\right]-\delta_{4} \theta,
$$


where the linear term $\delta_{4} \theta$ is considered as a part of leaking fiscal revenue captured by the policymakers. The loss function (16) is similar to that of Bohn (2013) except that it also includes the political costs associated with corruption, i.e., $\delta_{3}(\theta-\bar{\theta})^{2}$. This allows comparing the results obtained here with those obtained in Section 4 and highlighting the effects uniquely associated with grand corruption. Taking into account the presence of $\delta_{4}$ in the government's loss function and solving the model as before lead to the equilibrium solutions similar to these given by (8)-(10) except for a term including $\delta_{4}$ (Appendix A.3).

For the cases of 'sanding-the-wheels' effect (i.e., $\psi<0$ ) and moderate 'greasing-thewheels' effect (i.e., $0<\psi<1$ ), the interior solutions for $\theta, \tau$ and $g$ exist if

$$
\Phi_{1}^{*} \equiv \Phi_{1}+\frac{(1-\psi)(1+\mu) \Theta}{B-(1+\mu) \Theta \delta_{3}} \delta_{4}<\bar{g}<\Phi_{2}+\frac{\mu \delta_{2}+(1+\mu) \Theta}{\delta_{2}(1-\psi)(1+\mu) \Theta} \delta_{4} \equiv \Phi_{2}^{*}
$$

where $\Phi_{1}^{*}>\Phi_{1}$ and $\Phi_{2}^{*}>\Phi_{2}, \forall \psi<1$. To ensure that condition (17) is verified, we must have $\Phi_{2}^{*}>\Phi_{1}^{*}$, implying that:

$$
u_{\min }>\Omega-\frac{\delta_{2}\left(B+\delta_{2} \delta_{3}\right) \mu}{(1-\psi)(1+\mu)\left[B-(1+\mu) \Theta \delta_{3}\right] \Theta} \equiv \Omega^{*} .
$$

This condition is less restrictive than (13).

When the 'greasing-the-wheels' effect is large (i.e., $\psi>1$ ), $\Phi_{1}$ and hence $\Phi_{1}^{*}$ are always negative, meaning that $g=\tau-\theta$ is always positive. The interior solution for $\theta$ exists if

$$
\bar{g}>\Phi_{2}^{\prime}+\frac{\mu \delta_{2}+(1+\mu) \Theta}{\delta_{2}(1-\psi)(1+\mu) \Theta} \delta_{4} \equiv \Phi_{2}^{\prime *},
$$

where $\Phi_{2}^{\prime *}<\Phi_{2}^{\prime}, \forall \psi>1$, implying that the condition for the existence of interior solutions is more restrictive when the government is non-benevolent than otherwise.

To simply the presentation, we consider only how the equilibrium solutions are altered by the introduction of grand corruption as well as its interactions with central bank opacity. Let upper indices ' $b$ ' and ' $\mathrm{b}$ ' denote the interior equilibrium solutions with a benevolent and a 
non-benevolent government, respectively. The difference between these two sets of equilibrium solutions is given by

$$
\begin{aligned}
& \pi^{n b}-\pi^{b}=\frac{1+\varepsilon}{\varepsilon-\mu}\left(x^{n b}-x^{b}\right)=\frac{(1+\varepsilon)(1-\psi) \delta_{2}}{B} \delta_{4}, \\
& \tau^{n b}-\tau^{b}=\frac{\mu \delta_{2}+(1+\mu) \psi \Theta}{B} \delta_{4}, \\
& \theta^{n b}-\theta^{b}=\frac{\mu \delta_{2}+(1+\mu) \Theta}{B} \delta_{4}>0, \\
& g^{n b}-g^{b}=\tau^{n b}-\tau^{b}-\left(\theta^{n b}-\theta^{b}\right)=\frac{(\psi-1)(1+\mu) \Theta}{B} \delta_{4} .
\end{aligned}
$$

Under the 'greasing-the-wheels' hypothesis, we distinguish two cases. If $0<\psi<1$, an increase in grand corruption (higher $\delta_{4}$ ) induces higher inflation, taxes and corruption but lower output gap and public expenditures. For $\psi>1$, its effects on inflation, the output gap and public expenditures are inversed while those on the tax rate and corruption remain the same. Under the 'sanding-the-wheels' hypothesis $(\psi<0)$, the effects of an increase in grand corruption are the same as in the case where $0<\psi<1$ as long as we have $-\frac{\mu \delta_{2}}{(1+\mu) \Theta}<\psi<0$. When the 'sanding-the-wheels' is sufficiently large, i.e., $\psi<-\frac{\mu \delta_{2}}{(1+\mu) \Theta}$, only the effect on the tax rate is inversed.

Since $B$ increases with $\Theta$ and the latter increases with $\sigma_{\varepsilon}^{2}$, it is straightforward to see from (20) that opacity moderates the impact of grand corruption on inflation and the output gap. Meanwhile, $\sigma_{\varepsilon}^{2}$ simultaneously affects the numerator and the denominator of (21)-(23).

It is easy to show that $\frac{\partial\left(\theta^{n b}-\theta^{b}\right)}{\partial \delta_{4}}$ decreases with $\sigma_{\varepsilon}^{2}$. In contract, $\frac{\partial\left(\tau^{n b}-\tau^{b}\right)}{\partial \delta_{4}}$ depends on the effect of corruption on the supply function and so does its reaction to an increase in $\sigma_{\varepsilon}^{2}$. When $-\frac{\mu \delta_{2}}{(1+\mu) \Theta}<\psi<1$ and $\psi>1+\frac{\delta_{3}}{\delta_{2}}$, we have $\frac{\partial\left(\tau^{n b}-\tau^{b}\right)}{\partial \delta_{4}}>0$ and $\frac{\partial^{2}\left(\tau^{n b}-\tau^{b}\right)}{\partial \delta_{4} \partial \sigma_{\varepsilon}^{2}}<0$, meaning that 
an increase in opacity attenuates the effect of grand corruption. For $\psi<-\frac{\mu \delta_{2}}{(1+\mu) \Theta}$, we have $\frac{\partial\left(\tau^{n b}-\tau^{b}\right)}{\partial \delta_{4}}<0$ and $\frac{\partial^{2}\left(\tau^{n b}-\tau^{b}\right)}{\partial \delta_{4} \partial \sigma_{\varepsilon}^{2}}<0$, and for $1<\psi<1+\frac{\delta_{3}}{\delta_{2}}$, we have $\frac{\partial\left(\tau^{n b}-\tau^{b}\right)}{\partial \delta_{4}}>0$ and $\frac{\partial^{2}\left(\tau^{n b}-\tau^{b}\right)}{\partial \delta_{4} \partial \sigma_{\varepsilon}^{2}}>0$. For these two cases, an increase in opacity reinforces the effect of grand corruption. Therefore, in association with grand corruption, the fiscal disciplining effect of opacity incites the government to moderate corruption and the tax rate only when 'sandingthe-wheels' and 'greasing-the-wheels' effects are moderate or when the 'greasing-the-wheels' effect is quite large.

Using (20), we obtain:

$$
\operatorname{var}\left(\pi^{n b}-\pi^{b}\right)=\operatorname{var}\left(x^{n b}-x^{b}\right)=\frac{(1-\psi)^{2} \delta_{2}^{2} \sigma_{\varepsilon}^{2} \delta_{4}^{2}}{B}
$$

Opacity affects $\operatorname{var}\left(\pi^{n b}-\pi^{b}\right)$ and $\operatorname{var}\left(x^{n b}-x^{b}\right)$ through the numerator (direct effect) and the denominator (disciplining effect reflected in $\Theta$ ). The disciplining effect of opacity dominates its direct effect only if the initial degree of opacity is sufficiently high, i.e. $\frac{\partial \operatorname{var}\left(\pi^{n b}-\pi^{b}\right)}{\partial \sigma_{\varepsilon}^{2}}=\frac{\partial \operatorname{var}\left(x^{n b}-x^{b}\right)}{\partial \sigma_{\varepsilon}^{2}}<0$ if $\sigma_{\varepsilon}^{2}>\frac{(1+\mu) \mu \delta_{2} \delta_{3}}{\left(1+\delta_{1}\right)\left[\delta_{3}+(\psi-1)^{2} \delta_{2}\right]}+\frac{\delta_{1}+\mu^{2}}{1+\delta_{1}}$, and vice versa. The last condition is the same as that in Proposition 3.

The introduction of grand corruption does not affect the equilibrium if the optimal solution of $\theta$ is negative because, in this case, the benchmark solutions (5)-(6) will prevail. The effects of opacity can then be similarly analysed as in Section 3. However, the presence of grand corruption makes this situation less likely.

\subsection{Public debt and seigniorage revenue}


Taking account of public debt and seigniorage revenue, the government's budget constraint (2) is rewritten as: ${ }^{17}$

$$
g_{t}+\left(1+r_{t-1}\right) d_{t-1}=k \pi_{t}+\tau_{t}+d_{t}-\theta
$$

where $k$ represents the real holdings of base money as share of output, $\pi_{t}$ the inflation rate, $d_{t}$ the amount of single-period public debt (as a ratio of output) issued in $t$ and re-paid one period after, and $r_{t}$ the real interest rate.

For given public expenditures, higher seigniorage revenue allows the government to reduce the tax rate. Thus, the central bank should let inflation be higher so as to reduce the effect on the output induced by distortionary taxes. On the other hand, by increasing the tax rate, the government could induce a higher inflation rate to boost the total fiscal revenue. Therefore, the inclusion of seigniorage revenue in the government's budget constraint could decrease the importance of the disciplining effect of opacity. The final effects of opacity are ambiguous, depending on the structural parameters of the model.

With public debt, the government has a supplementary instrument to spread the cost of financing current public expenditures over time. Public debt, relaxing the current budget constraint, allows the government to reduce the tax rate, and to increase corruption and public expenditures. The fiscal authority's optimisation now requires balancing various effects on social welfare induced by an increase in public debt.

A rise in the first period's public borrowing has a favourable effect on current macroeconomic performance (lower inflation and seigniorage revenue, and higher output and public expenditure gap) but an unfavourable effect on the performance of future periods.

\footnotetext{
17 Following Alesina and Tabellini (1987), we derive equation (24) in two steps. First, we write the government budget constraint in nominal terms as $G_{t}+\left(1+i_{t-1}\right) D_{t-1}=\left(\tau_{t}-\theta\right) P_{t} X_{t}+D_{t}+M_{t}-M_{t-1}$, where $G_{t}$ denotes public spending, $P_{t}$ price level, $X_{t}$ real output, $M_{t}$ money supply, $D_{t}$ nominal public debt, and $i_{t}$ nominal interest rate, respectively. We assume that money demand can be specified according to a simplified quantity theory such that $M_{t}=k P_{t} X_{t}$. Second, dividing both sides by nominal income $P_{t} X_{t}$ and neglecting the terms associated with the growth rate of real output $\left(X_{t}-X_{t-1}\right) / X_{t-1}$, we obtain equation (24).
} 
Under both the 'greasing-the-wheel' and 'sanding-the-wheel' hypotheses, the policymaker can tolerate a higher level of corruption while financing current popularity-enhancing public expenditures with the help of the intertemporal policy instruments $\left(d_{t}\right)$, while not hampering output and inflation performance. If the government is appointed for one period and wants to be re-elected, it must therefore appraise the intertemporal arbitrage between current and future welfare effects of a higher public debt.

In such a framework, the government will be motivated to totally counterbalance the negative effects of opacity on social welfare if it has enough instruments at its disposal. This is more likely when the government can issue public debt to finance current public expenditures and does not care much about social welfare in future periods. With public debt, the government has more policy instruments than objectives and could generally neutralise the effect of opacity on the economy if the corruption has a sufficiently large 'greasing-thewheels' effect. Otherwise, i.e. if the latter is relatively small or when corruption has a 'sanding-the-wheels' effect, the government has to fight corruption with greater effort, and therefore the disciplining effect of opacity prevails.

\subsection{Costly corruption fighting}

In the budget constraint (2), we have neglected the fact that fighting corruption could be costly and need financial resources. A more elaborate formulation of the budget constraint which explicitly takes into account the cost of fighting corruption could be

$$
g=\tau-\theta-\beta\left(\theta_{0}-\theta\right)
$$

where $\beta\left(\theta-\theta_{0}\right)$ measures the cost of fighting corruption with $\left(\theta_{0}-\theta\right)$ representing reduction in corruption from its previous level $\theta_{0}$. Compared with the budget constraint (2), this formulation will change the threshold conditions for the equilibrium effects of opacity. 
The main effect of such costs is that they reduce the incentive of the government to fight corruption and hence to reduce the tax rate, leading the government to be less inclined to observe the fiscal discipline imposed by central bank opacity. This implies that, the fiscal disciplining effect of opacity will prevail only for a 'sanding-the-wheels' effect of corruption or a smaller 'greasing-the-wheels' effect than in the absence of these costs.

\subsection{Implications of a Nash game}

The prior analyses and discussions are founded on the hypothesis that the government and the central bank play a Stackelberg game, which reflects a situation where the government sets its fiscal policy once a year and the central bank makes monetary policy decisions on many occasions during the year. In practice, important fiscal policy decisions could also be taken as frequently as monetary policy decisions. This observation brings us to consider the implications of a Nash game between the government and the central bank.

At the Nash equilibrium of the benchmark model, central bank opacity is likely to induce higher inflation expectations and hence higher inflation for a given preference shock $\varepsilon$. In effect, the government does not make any commitment to its decisions in the Nash game. This leads the central bank to doubt if opacity could discipline enough fiscal authorities and hence to consider that the latter will not moderate public expenditures and taxes. Accordingly, the government is not incited to restrict its taxes and public expenditures. These fiscal and monetary interactions in the Nash game imply that opacity induces higher inflation, a lower output gap and a higher macroeconomic volatility, despite the existence of fiscal disciplining effect (Dai and Sidiropoulos, 2011). These results could be generalised to the framework where the government has an objective of stabilising corruption.

Without providing analytical solutions, we make some observations by comparing the role of opacity and grand corruption in Stackelberg and Nash settings. In the Stackelberg setup it 
appears that opacity and grand corruption have opposing effects on inflation. Opacity generally plays the role of a 'commitment device' because it exerts fiscal discipline which, in turn, allows the central bank as the follower to pursue a low inflation policy. In contrast, grand corruption cannot serve as a commitment device because the central bank cannot restrict the level of grand corruption by choosing a contractionary monetary policy except when the 'greasing-the-wheels' effect is strong enough. In the Nash game where the central bank and the government act simultaneously, opacity would not be effective as commitment device for achieving lower inflation and would in the contrary generate higher inflation for given preference shock $\varepsilon$. Grand corruption would act similarly as in the Stackelberg setting, i.e. it could be a commitment device to reduce inflation, only if the 'greasing-the-wheels' effect is sufficiently high. ${ }^{18}$

\section{Conclusions}

This paper analyses fiscal and monetary policy interactions in a Stackelberg game within a model with three types of distortions, i.e., opacity about central bank preferences, distortionary taxes, and corruption. The latter is modelled as a net loss of fiscal resources, with either a 'sanding-the-wheels' or 'greasing-the-wheels' effect on the supply function.

We have first analysed the effects of central bank opacity in a benchmark model without corruption. In such a model, an increase in opacity has a fiscal disciplining effect, leading to lower inflation, tax rate, and public expenditures and higher output. In the absence of supply shocks, the fiscal disciplining effect could induce a smaller macroeconomic volatility only if

\footnotetext{
${ }^{18}$ In a Nash setting, grand corruption has a moderating effect on inflation according to Bohn (2013) because a less expansionary (low inflation) policy would limit the government's expropriation possibilities. Thus, grand corruption acts as a commitment device for monetary policy. Given that our model (with distortionary taxes and without budget deficits) is different from that of Bohn (without distortionary taxes but with budget deficits), the role of grand corruption as commitment device is also different. The reason is that the effect of budget deficits is similar to that of public debt, which allows improving the current macroeconomic performance and hence the effects on inflation associated with grand corruption.
} 
the initial degree of opacity is sufficiently high and this is more likely if the government is less concerned with public expenditure deviations. Central bank opacity moderates the effects of supply shocks on inflation and the output gap but amplifies the variations of the tax rate and public expenditures.

The introduction of corruption gives the government more trade-offs to consider but also one more instrument, leading to significant changes in the effects of opacity by reducing the 'fiscal discipline' parameter space when the 'greasing-the-wheels' effect is sufficiently large. The effects of opacity on inflation and the output gap mainly depend on the relative importance of the effects of distortionary taxes and corruption on the supply function and on whether the government has an objective of stabilising corruption.

If the benevolent government ignores political costs of corruption and does not desire to stabilise corruption around a target, it has more free policy instruments than objectives. It is shown that the government can fully neutralise the effects of supply shocks and central bank opacity if the 'greasing-the-wheels' effect of corruption is sufficiently large. When the 'greasing-the-wheels' effect is relatively small or when corruption has a 'sanding-the-wheels' effect, the government chooses to completely eliminate corruption and sets the tax rate and public expenditures at values identical to those obtained in the benchmark model, leading to identical equilibrium solutions.

Adding an objective of stabilising corruption, the benevolent government will no longer be able to neutralise the effects of opacity. In the absence of supply shocks, under the 'sanding-the-wheels' hypothesis, opacity would generally have a fiscal disciplining effect by reducing public expenditures, the tax rate, corruption as well as inflation. If the 'greasing-thewheels' effect is relatively moderate, greater opacity would induce lower inflation, and higher output and corruption. Greater opacity lowers the tax rate when the 'greasing-the-wheels' effect is moderate or high enough. Under both 'sanding-the-wheels' and 'greasing-the- 
wheels' hypotheses, greater opacity reduces the volatility of inflation and the output gap if the initial degree of opacity is sufficiently high such that the fiscal disciplining effect of opacity dominates its direct effect. Moreover, greater opacity attenuates the effects of supply shocks on the level and volatility of inflation and the output gap independently of the effect of corruption on the supply function, but amplifies these on the tax rate and corruption if the 'greasing-the-wheels' effect is relatively large.

The model can be extended in various directions with potentially important policy implications. Our preliminary analyses suggest that introducing grand corruption in the government's objective function reinforces our main findings while the inclusion of public debt and the exclusion of political costs allow the government to neutralise the effects of opacity. Including the costs of corruption fighting in the budget constraint, by reducing the incentive of the government to fight corruption and therefore the tax rate, would lead the government to be less inclined to observe the fiscal discipline imposed by opacity. A shift from a Stackelberg to a Nash game structure would considerably reduce the possibility for the fiscal disciplining effect of opacity to be a dominant determinant of the government's behaviour. The inclusion of seigniorage revenue in the government's budget constraint would make the effects of opacity ambiguous. Other extensions which are appropriate in the context of emerging market economies affected by corruption, such as the optimal choice of central bank independence, uncertainty about the targets of inflation and the output gap, and the dependence of the 'sanding-the-wheels' or greasing-the-wheels' effect on the level of corruption, could also be promising.

\section{References:}

Agell, Jonas, Lars Calmfors and Gunnar Jonsson (1996), "Fiscal Policy when Monetary Policy Is Tied to the Mast,"European Economic Review 40, 1413-1440.

Aidt, T. (2003), "Economic Analysis of Corruption: A Survey," Economic Journal 113, 632-652.

Aidt, Toke S. (2009), "Corruption, institutions, and economic development," Oxford Review of Economic Policy 25(2), 271-291. 
Alesina, A. and G. Tabellini (1987), "Rules and Discretion with Noncoordinated Monetary and Fiscal Policies," Economic Inquiry 25, 619-630.

Al-Marhubi, F. (2000), “Corruption and inflation,” Economics Letters 66, 199-202.

Arnone, Marco, Bernard J. Laurens, Jean-François Segalotto and Martin Sommer (2009), "Central Bank Autonomy: Lessons from Global Trends," IMF Staff Papers 56(2), 263-296.

Barreto, R. (2000), "Endogenous Corruption in a Neoclassical Growth Model," European Economic Review 44 (1), 35-60.

Beetsma, R.M.W.J., and H. Jensen (2003), "Why money talks and wealth wispers: Monetary uncertainty and mystique. A comment," Journal of Money, Credit, and Banking 35, 129-136.

Blackburn, K., and G. F. Forgues-Puccio (2007), "Distribution and Development in a Model of Misgovernance," European Economic Review 51, 1534-1563.

Blackburn, K., and J. Powell (2011), "Corruption, inflation and growth," Economics Letters 113(3), 225-227.

Blinder, Alan S. (1998), Central Banking in Theory and Practice. MIT Press, Cambridge, MA.

Blinder, Alan S., Charles A. Goodhart, Philipp M. Hildebrand, David Lipton, and Charles Wyplosz (2001), How Do Central Banks Talk? Geneva Reports on the World Economy 3.

Bohn, Frank (2013), "Grand Corruption Instead of Commitment? Reconsidering Time-Inconsistency of Monetary Policy," Journal of International Money and Finance 32, 478-490.

Brainard, W.C. (1967) "Uncertainty and the effectiveness of policy," American Economic Review 57, 411-25.

Campos, J.E., D. Lien, and S. Pradhan (1999), "The Impact of Corruption on Investment: Predictability Matters," World Development 27 (6), 1059-1067.

Chortareas, G., D. Stasavage and G. Sterne (2002), "Does it pay to be transparent? International evidence from central bank forecasts," Federal Reserve Bank of St. Louis Review 84(4), 99-117.

Ciccarone, Giuseppe, Enrico Marchetti and Giovanni Di Bartolomeo (2007), "Unions, fiscal policy and central bank transparency," The Manchester School 75, 617-633.

Coppier, R. and E. Michetti (2006), "Corruption vs Production. A Non-Linear Relationship," Economic Modelling 23, 622-637.

Coppier, R., and G. Piga (2004), "Do 'clean hands' ensure healthy growth?, Theory and practice in the battle against corruption," Quaderno di Dipartimento di Istituzioni Economiche e Finanziarie 21, University of Macerata, Italy.

Cukierman, Alex, and Alan Meltzer (1986), "A Theory of Ambiguity, Credibility and Inflation Under Discretion and Asymmetric Information," Econometrica 54, 1099-1128.

Dai, Meixing and Moïse Sidiropoulos (2011), "Fiscal disciplining effect of central bank opacity: Stackelberg versus Nash equilibrium," Economics Bulletin 31(4), 3068-3076.

Dal Bó, E., and M. A. Rossi (2007), "Corruption and Inefficiency: Theory and Evidence from Electric Utilities," Journal of Public Economics 91, 939-962.

de Mendonça, Helder Ferreira and José Simão Filho (2008), "Macroeconomic Effects of Central Bank Transparency: The Case of Brazil," Cato Journal 28(1), 117-137.

De Vual, A., and Ebben, W. (2011), "Institutions and the Relation between Corruption and Economic Growth," Review of Development Economics 15(1), 108-123.

Del Monte, A. and E. Papagni (2001), "Public Expenditure, Corruption and Economic Growth: The Case of Italy," European Journal of Political Economy 17, 1-16.

Demertzis, Maria and A. Hughes Hallet (2007), "Central Bank Transparency in Theory and Practice", Journal of Macroeconomics 29(4), 760-789.

Demertzis, Maria, Andrew Hughes Hallett and Nicola Viegi (2004), "An Independent Central Bank Faced with Elected Governments," European Journal of Political Economy 20, 907-922.

Dincer, N. Nergiz and Barry Eichengreen (2007), "Central Bank Transparency: Where, Why, and with What Effects?" NBER Working Paper 13003.

Du, Julan and Wei, Shang-Jin (2004), “Does insider trading raise stock market variability?” Economic Journal 114, 927-956.

Eijffinger, S.C.W. and van der Cruijsen, C. (2010), "The Economic Impact of Central Bank Transparency: A Survey," in: P. Siklos, M. Bohl and M. Wohar(eds.), Challenges in central banking: The present institutional environment and the forces affecting the conduct of monetary policy, Cambridge University Press, 261-319. 
Eijffinger, S.C.W., M. Hoeberichts, and E. Schaling (2000), "Why money talks and wealth whispers: Monetary uncertainty and mystique," Journal of Money, Credit and Banking 32(2), 218-235.

Eijffinger, Sylvester C.W., and Petra M. Geraats (2006), "How transparent are central banks?," European Journal of Political Economy 22(1), 1-21.

Faust, J., and L. Svensson (2001), "Transparency and credibility: Monetary policy with unobservable goals," International Economic Review 42, 369-407.

Fisman, R., and S.-J. Wei (2004), "Tax Rates and Tax Evasion: Evidence from 'Missing Imports' in China," Journal of Political Economy 112 (2), 471-496.

Geraats, Petra M. (2002), "Central Bank Transparency," Economic Journal 112, 532-565.

Hefeker, Carsten (2010), "Taxation, Corruption and the Exchange Rate Regime," Journal of Macroeconomics 32 (1), 338-346.

Hefeker, Carsten, and Blandine Zimmer (2011), "Uncertainty and Fiscal Policy in an Asymmetric Monetary Union," Open Economies Review 22 (1), 163-178.

Hoeberichts, Marco, Mewael F. Tesfaselassie and Sylvester Eijffinger (2009), "Central bank communication and output stabilisation," Oxford Economic Papers 61(2), 395-411.

Huang, H., and S.-J. Wei (2006), "Monetary Policies for Developing Countries: The Role of Institutional Quality," Journal of International Economics 70, 239-252.

Hughes-Hallett, A., and Viegi, N. (2003), "Imperfect transparency and the strategic use of private information in monetary policy: An ever present temptation for central bankers," The Manchester School 71, 498-520.

Jensen, H., (2002), "Optimal degrees of transparency in monetary policy making," Scandinavian Journal of Economics 104, 399-422.

Kaufmann, D., and S.-J. Wei (1999), "Does 'Grease Payment' Speed Up the Wheels of Commerce?" NBER Working Paper Series No.7093.

Kaufmann, Daniel, Aart Kraay and Massimo Mastruzzi (2007), "Governance Matters VI: Governance Indicators for 1996-2006," World Bank Policy Research Working Paper No. 4280.

Lambert-Mogiliansky, Ariane, Mukul Majumdar and Roy Radner (2007), "Strategic analysis of petty corruption: Entrepreneurs and bureaucrats," Journal of Development Economics 83, 351-367.

Leff, N. H. (1964), "Economic Development through Bureaucratic Corruption," American Behavioral Scientist 8(3), 8-14.

Mauro, P. (1995), “Corruption and Growth,” Quarterly Journal of Economics 110, 681-712.

Méon, Pierre-Guillaume, and Khalid Sekkat (2005), "Does corruption grease or sand the wheels of growth?" Public Choice 122(1), 69-97.

Méon, Pierre-Guillaume and Laurent Weill (2010), "Is Corruption an Efficient Grease?" World Development 38(3), 244-259.

Popkova, Katherina (2010), "Can the exchange rate regime influence corruption?," East-West Journal of Economics and Business 13(2), 107-124.

Rhee, J., and Nurlan Turdaliev (2010), "Aggregate shock and monetary policy regimes," Journal of Macroeconomics 32, 201-217.

Rogoff, K. (1985), "The optimal degree of commitment to an intermediate monetary target," Quarterly Journal of Economics 100(4), 1169-1190.

Rose-Ackerman, Susan (1975), "The economics of corruption," Journal of Public Economics 4(2), 187-203.

Shleifer, Andrei, and Robert Vishny (1993), “Corruption,” Quarterly Journal of Economics 108, 599617.

Sibert, A. (2002), "Monetary policy with uncertain central bank preferences," European Economic Review 46, 1093-1109.

Smith-Hillman, A.V. (2007), "Competition policy, inflation and corruption: evidence from African economies," Applied Economics Letters 14, 653-656.

Sorensen, J.R. (1991), "Political uncertainty and macroeconomic performance," Economics Letters 37, 377-381.

Transparency International (2012), Corruption Perception Index.

Wei, Shang-Jin (2000), "How taxing is corruption on international investors," Review of Economics and Statistics 82(1), 1-11. 
Westelius, N.J. (2009), "Imperfect transparency and shifts in the central bank's output gap target," Journal of Economic Dynamics \& Control 33, 985-996.

Wilson, Berry, and Anthony Saunders (2004), "Monetary secrecy and selective disclosure: The emerging market case of Mexico's monetary reporting," Review of Financial Economics 13(12), $199-210$.

Wu, Yi (2008), "The Role of Institutional Quality in a Currency Crisis Model," International Monetary Fund, Working Paper WP/08/5.

\section{Appendix A: The equilibriums solutions of the model and its variants}

\section{A.1. The solution of the model with a target for corruption (section 4)}

Minimising (4) subject to (1) yields the central bank's reaction function:

$$
\pi=\frac{(1+\varepsilon)\left(\tau-\psi \theta+\pi^{e}-u\right)}{1+\mu}
$$

Substituting $\pi$ given by (A.1) into (1) gives

$$
x=\frac{(\varepsilon-\mu)\left(\tau-\psi \theta+\pi^{e}-u\right)}{(1+\mu)} .
$$

Facing uncertainty about central bank preferences, the government minimises (3) subject to (1)-(2) and (A.1). The first-order conditions of the government's minimisation problem are

$$
\begin{aligned}
& \frac{\partial L^{G}}{\partial \tau}=0 \Rightarrow \Theta\left(\tau-\psi \theta+\pi^{e}-u\right)+\delta_{2}(\tau-\theta-\bar{g})=0 \\
& \frac{\partial L^{G}}{\partial \theta}=0 \Rightarrow-\psi \Theta\left(\tau-\psi \theta+\pi^{e}-u\right)-\delta_{2}(\tau-\theta-\bar{g})+\delta_{3}(\theta-\bar{\theta})=0 .
\end{aligned}
$$

where $\Theta \equiv \mathrm{E}\left[\frac{\delta_{1}(1+\varepsilon)^{2}+(\varepsilon-\mu)^{2}}{(1+\mu)^{2}}\right] \cong \frac{\delta_{1}+\mu^{2}+\left(1+\delta_{1}\right) \sigma_{\varepsilon}^{2}}{(1+\mu)^{2}}$, i.e., a second-order Taylor approximation.

The first-order conditions (A.3)-(A.4) lead to the government to set:

$$
\begin{aligned}
& \tau=\frac{\delta_{2}\left[(\psi-1) \psi \Theta+\delta_{3}\right] \bar{g}+\left[(\psi-1) \delta_{2}-\delta_{3}\right] \Theta\left(\pi^{e}-u\right)+\delta_{3}\left(\psi \Theta+\delta_{2}\right) \bar{\theta}}{\left(\Theta+\delta_{2}\right) \delta_{3}+(\psi-1)^{2} \Theta \delta_{2}}, \\
& \theta=\frac{\left(\Theta+\delta_{2}\right) \delta_{3} \bar{\theta}+\delta_{2}(\psi-1) \Theta\left(\pi^{e}-u\right)+(\psi-1) \Theta \delta_{2} \bar{g}}{\left(\Theta+\delta_{2}\right) \delta_{3}+(\psi-1)^{2} \Theta \delta_{2}} .
\end{aligned}
$$

Using (A.1), (A.5) and (A.6) and imposing the rational expectations hypothesis yield 


$$
\pi^{e}=\frac{\delta_{2} \delta_{3} \bar{g}+(1-\psi) \delta_{2} \delta_{3} \bar{\theta}}{\mu \delta_{2} \delta_{3}+(1+\mu) \Theta \delta_{3}+(1+\mu)(\psi-1)^{2} \delta_{2} \Theta} .
$$

Substituting $\pi^{e}$ given by (A.7) into (A.1)-(A.2) and (A.5)-(A.6) yields the interior equilibrium solutions (8)-(10).

The corner solutions for $\delta_{3}>0$ or $\delta_{3}=0$ are identical under 'greasing-the-wheels' and 'sanding the wheels' hypotheses. To obtain these solutions, consider that among the two firstorder conditions (A.3) and (A.4), only the first is binding for $\theta \geq 0$. The inequality $\frac{\partial L^{G}}{\partial \theta}>0$ means that if we can reduce $\theta$ below the zero lower bound, we can still increase the social welfare. Given that we cannot reduce corruption to a negative level, we impose $\theta=0$. Imposing $\theta=0$ means that the value of $\delta_{3}$ does not play a role anymore in determining the equilibrium solutions. Using $\theta=0$ and (A.3), we obtain the tax rate set by the government:

$$
\tau=\frac{\delta_{2} \bar{g}-\Theta\left(\pi^{e}-u\right)}{\Theta+\delta_{2}}
$$

Substituting $\theta=0$ and $\tau$ given by (A.8) in (A.1) and imposing the rational expectations hypothesis yield

$$
\pi^{e}=\frac{\delta_{2} \bar{g}}{(1+\mu) \Theta+\delta_{2} \mu}
$$

Using $\theta=0$, (3), (A.1)-(A.2), (A.8)-(A.9) and $\Theta \cong \frac{\delta_{1}+\mu^{2}+\left(1+\delta_{1}\right) \sigma_{\varepsilon}^{2}}{(1+\mu)^{2}}$, we obtain the solutions of $\pi, x, \tau$ and $g$, which are identical to the benchmark solutions (5)-(6).

\section{A.2. The solution of the benchmark model (Section 3)}

To obtain the solutions of the benchmark model (5)-(6), we can either resolve the model from the beginning as in Appendix A.1 by imposing $\psi=\delta_{3}=0$ or taking the solutions (8)(10) while imposing $\psi=0$ and $\delta_{3} \rightarrow \infty$. 


\section{A.3. The model with grand corruption (Subsection 5.1)}

Given the government's loss function (16), the first-order condition (A.4) is modified as follows

$$
\frac{\partial L^{G}}{\partial \theta}=0 \Rightarrow-\psi \Theta\left(\tau-\psi \theta+\pi^{e}-u\right)-\delta_{2}(\tau-\theta-\bar{g})+\delta_{3}(\theta-\bar{\theta})-\delta_{4}=0
$$

Compared to (A.4), the only change observed here is the presence of $\delta_{4}$ in (A.10). Taking this into account and solving the model as in Appendix A.1 lead to the equilibrium solutions, whose difference with solutions (8)-(10) given in (20)-(22) is due uniquely to $\delta_{4}$.

A negative optimal solution of $\theta$ implies that for $\theta \geq 0$, we have $\frac{\partial L^{G}}{\partial \theta}>0$. Comparing (A.10) with (A.4), the presence of grand corruption makes this situation less likely. Solving the model for $\theta=0$, we obtain solutions identical to the benchmark solutions (5)-(6).

\section{Appendix B: Proof of Propositions 2a}

Deriving $\pi, \tau$ and $\theta$ given by (8)-(10) with respect to $\sigma_{\varepsilon}^{2}$ while setting $u=0$ yields:

$$
\begin{aligned}
& \left.\frac{\partial \pi}{\partial \sigma_{\varepsilon}^{2}}\right|_{u=0}=\left.\frac{1+\varepsilon}{\varepsilon-\mu} \frac{\partial x}{\partial \sigma_{\varepsilon}^{2}}\right|_{u=0}=\frac{-\delta_{2} \delta_{3}(1+\varepsilon)(1+\mu)[\bar{g}-(\psi-1) \bar{\theta}]\left[\delta_{3}+(\psi-1)^{2} \delta_{2}\right]}{B^{2}} \frac{\partial \Theta}{\partial \sigma_{\varepsilon}^{2}}, \\
& \left.\frac{\partial \tau}{\partial \sigma_{\varepsilon}^{2}}\right|_{u=0}=\frac{\delta_{2} \delta_{3} \mu(1+\mu)\left[(\psi-1) \delta_{2}-\delta_{3}\right][\bar{g}-(\psi-1) \bar{\theta}]}{B^{2}} \frac{\partial \Theta}{\partial \sigma_{\varepsilon}^{2}} \\
& \left.\frac{\partial \theta}{\partial \sigma_{\varepsilon}^{2}}\right|_{u=0}=\frac{\delta_{2}^{2} \delta_{3} \mu(\psi-1)[\bar{g}-(\psi-1) \bar{\theta}](1+\mu)}{B^{2}} \frac{\partial \Theta}{\partial \sigma_{\varepsilon}^{2}} \\
& \left.\frac{\partial g}{\partial \sigma_{\varepsilon}^{2}}\right|_{u=0}=\left.\frac{\partial \tau}{\partial \sigma_{\varepsilon}^{2}}\right|_{u=0}-\left.\frac{\partial \theta}{\partial \sigma_{\varepsilon}^{2}}\right|_{u=0}=\frac{-\delta_{2} \delta_{3}^{2} \mu(1+\mu)[\bar{g}-(\psi-1) \bar{\theta}]}{B^{2}} \frac{\partial \Theta}{\partial \sigma_{\varepsilon}^{2}}
\end{aligned}
$$


where $\frac{\partial \Theta}{\partial \sigma_{\varepsilon}^{2}}=\frac{1+\delta_{1}}{(1+\mu)^{2}}>0$. For $u=0$, the signs of $\frac{\partial \pi}{\partial \sigma_{\varepsilon}^{2}}, \frac{\partial x}{\partial \sigma_{\varepsilon}^{2}}, \frac{\partial \tau}{\partial \sigma_{\varepsilon}^{2}}, \frac{\partial \theta}{\partial \sigma_{\varepsilon}^{2}}$ and $\frac{\partial g}{\partial \sigma_{\varepsilon}^{2}}$ critically depend on that of $[\bar{g}-(\psi-1) \bar{\theta}]$ while the sign of $\frac{\partial \tau}{\partial \sigma_{\varepsilon}^{2}}$ also depends on that of $\left[(\psi-1) \delta_{2}-\delta_{3}\right]$. Taking account of the condition $\mu-\varepsilon>0$, we obtain the conditions ensuring the results reported in Proposition 2a.

\section{Appendix C: Proof of Propositions 2b}

Deriving $\pi, \tau$ and $\theta$ given by (8)-(10) with respect to $\sigma_{\varepsilon}^{2}$ and $u$ yields:

$$
\begin{aligned}
& \frac{\partial^{2} \pi}{\partial u \partial \sigma_{\varepsilon}^{2}}=\frac{1+\varepsilon}{\varepsilon-\mu} \frac{\partial^{2} x}{\partial u \partial \sigma_{\varepsilon}^{2}}=\frac{\delta_{2} \delta_{3}(1+\varepsilon)(1+\mu)\left[\delta_{3}+(\psi-1)^{2} \delta_{2}\right]}{\left(B+\delta_{2} \delta_{3}\right)^{2}} \frac{\partial \Theta}{\partial \sigma_{\varepsilon}^{2}}>0, \\
& \frac{\partial^{2} \tau}{\partial u \partial \sigma_{\varepsilon}^{2}}=-\frac{\delta_{2} \delta_{3}(1+\mu)^{2}\left[(\psi-1) \delta_{2}-\delta_{3}\right]}{\left(B+\delta_{2} \delta_{3}\right)^{2}} \frac{\partial \Theta}{\partial \sigma_{\varepsilon}^{2}}, \\
& \frac{\partial^{2} \theta}{\partial u \partial \sigma_{\varepsilon}^{2}}=-\frac{\delta_{2}^{2} \delta_{3}(\psi-1)(1+\mu)^{2}}{\left(B+\delta_{2} \delta_{3}\right)^{2}} \frac{\partial \Theta}{\partial \sigma_{\varepsilon}^{2}},
\end{aligned}
$$

Given that $\frac{\partial \Theta}{\partial \sigma_{\varepsilon}^{2}}>0$, we have $\frac{\partial^{2} \tau}{\partial u \partial \sigma_{\varepsilon}^{2}}<0$ if $\psi>1+\frac{\delta_{3}}{\delta_{2}}$ and vice versa, and $\frac{\partial^{2} \theta}{\partial u \partial \sigma_{\varepsilon}^{2}}<0$ if $\psi>1$ and vice versa. Comparing (C.1)-(C.3) with $\frac{\partial \pi}{\partial u}, \frac{\partial x}{\partial u}, \frac{\partial \tau}{\partial u}$ and $\frac{\partial \theta}{\partial u}$ obtained using (8)-(10) leads to Proposition $2 b$.

\section{Appendix D: Proof of Propositions 3}

Deriving (15) with respect to $\sigma_{\varepsilon}^{2}$ and using the approximated value of $\Theta$ lead to

$$
\begin{aligned}
\frac{\partial \operatorname{var}(\pi)}{\partial \sigma_{\varepsilon}^{2}}= & \frac{\partial \operatorname{var}(x)}{\partial \sigma_{\varepsilon}^{2}}=\frac{\delta_{2}^{2} \delta_{3}^{2}[\bar{g}+(1-\psi) \bar{\theta}]^{2}\left\{(1+\mu) \mu \delta_{2} \delta_{3}+\left[\delta_{3}+(\psi-1)^{2} \delta_{2}\right]\left[\delta_{1}+\mu^{2}-\left(1+\delta_{1}\right) \sigma_{\varepsilon}^{2}\right]\right\}}{(1+\mu) B^{3}} \\
& -\frac{2 \delta_{2}^{2} \delta_{3}^{2} \sigma_{u}^{2}\left(1+\delta_{1}\right)\left[\delta_{3}+(\psi-1)^{2} \delta_{2}\right]}{(1+\mu)\left(B+\delta_{2} \delta_{3}\right)^{3}} .
\end{aligned}
$$

In the absence of supply shocks, we obtain $\frac{\partial \operatorname{var}(\pi)}{\partial \sigma_{\varepsilon}^{2}}=\frac{\partial \operatorname{var}(x)}{\partial \sigma_{\varepsilon}^{2}}<0$ if $\sigma_{\varepsilon}^{2}>\frac{(1+\mu) \mu \delta_{2} \delta_{3}}{\left(1+\delta_{1}\right)\left[\delta_{3}+(\psi-1)^{2} \delta_{2}\right]}+\frac{\delta_{1}+\mu^{2}}{1+\delta_{1}}$. 